\title{
Protocolo de atención odontológica en niños con Epidermólisis Ampollar
}

\section{Resumen}

La atención odontológica de los niños con Epidermólisis ampollar (EA) o bullosa (EB) son un inmenso desafío para la práctica odontológica ya que se trata de un grupo de trastornos hereditarios que manifiestan aparición de ampollas en piel y mucosas al roce o suave trauma. Presentan múltiples manifestaciones orofaciales que requieren de un protocolo de atención interdisciplinaria específico que comprenda un alto componente preventivo. Se describirán los principales ítems del mismo y las posibilidades de rehabilitación bucal integral personalizada.

Palabras clave: epidermólisis bullosa, ampollas, interdisciplina, prevención bucal, tratamiento rehabilitador.

Artigo de revisão

\section{Protocolo de atendimento odontológico para crianças com epidermólise bolhosa}

\section{Resumo}

A atenção odontológica de crianças com Epidermólise bolhosa (EB) é um grande desafio para a prática odontológica já que é um grupo de doenças hereditárias que se manifestam pelo aparecimento de bolhas na pele e mucosas causadas por fricção ou trauma leve. Apresentam múltiplas manifestações orofaciais que requerem um protocolo de atenção interdisciplinar específico que inclua um grande componente preventivo. Serão descritos os principais pontos do mesmo e as possibilidades de reabilitação bucal integral individualizada.

Palavras-chave: epidermólise bolhosa, bolhas, a prevenção oral.

Review article

\section{Dental care protocol for children with epidermolysis bullosa}

\section{Summary}

Dental care for children with epidermolysis bullosa (EB) is an immense challenge for dental practice as it is a group of inherited disorders that manifest blistering of skin and mucous membranes due to soft brush or trauma. They

\footnotetext{
${ }^{1}$ Especialista en Odontopediatría. Immediate Past President International Association for Disability and Oral Health iADH. Docente autorizada de la Facultad de Odontología Universidad de Buenos Aires. Miembro del Comité Editor del British Journal of Disability and Oral Health
} 
have multiple orofacial manifestations requiring a specific interdisciplinary treatment protocol that includes a high preventive component. The most important items will be described and the possibilities of personalized comprehensive oral rehabilitation.

Key words: epidermolysis bullosa, blisters, interdisciplinary team, oral prevention, rehabilitation treatment.

\section{Introducción}

La epidermólisis ampollar (EA) o bullosa (EB) es un grupo de enfermedades de la piel poco frecuentes de origen genético (Gráfico 2) que se caracterizan por una fragilidad epitelial que supone la formación de ampollas y vesículas en la piel y en las mucosas (boca, esófago, faringe, estómago, intestino, vías respiratorias y urinarias, párpados y córnea). Suelen ser llamados "niños mariposa" por la fragilidad de piel similar a las alas de las mismas, "bebés de algodón" y en Sudamérica "niños con piel de cristal".

La prevalencia es de 1 cada 17000 nacidos vivos, no muestra predilección por raza ni etnia (1) y afecta a ambos sexos por igual.

Es una condición que es siempre dolorosa, con frecuencia provoca discapacidad severa y po-

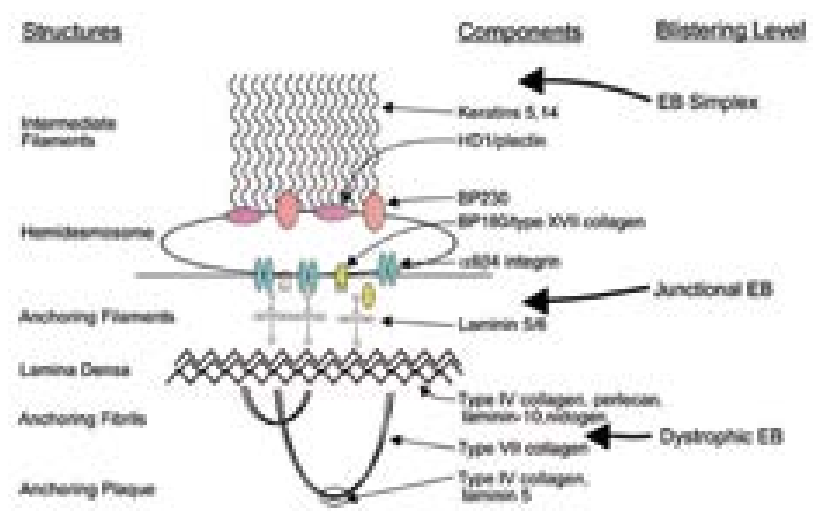

Gráfico 1. Marincovic. tencialmente mortal y, en sus formas más graves, mortales en la infancia. (1-2)

La clasificación es compleja y los primeros intentos se hicieron basándose en observaciones clínicas y genéticas. En la actualidad el diagnóstico específico se hace comúnmente por estudio histopatológico con microscopía electrónica de transmisión, complementado con microscopía convencional, análisis histoquímico y estudio molecular de los genes de las proteínas involucradas. (2)

\section{Descripción}

Actualmente existen tres tipos principales de la enfermedad reconocida, y estos se definen por la profundidad en la piel en la que se produce la formación de ampollas (Gráfico 1).

\section{Epidermolisis ampollar simple (EAS)}

Las ampollas se forman por la desintegración de las células de las membranas basal y suprabasal y la separación es intraepidérmica. El desarrollo del pelo, dientes y uñas puede ser normal. Las ampollas aparecen durante el primer año de

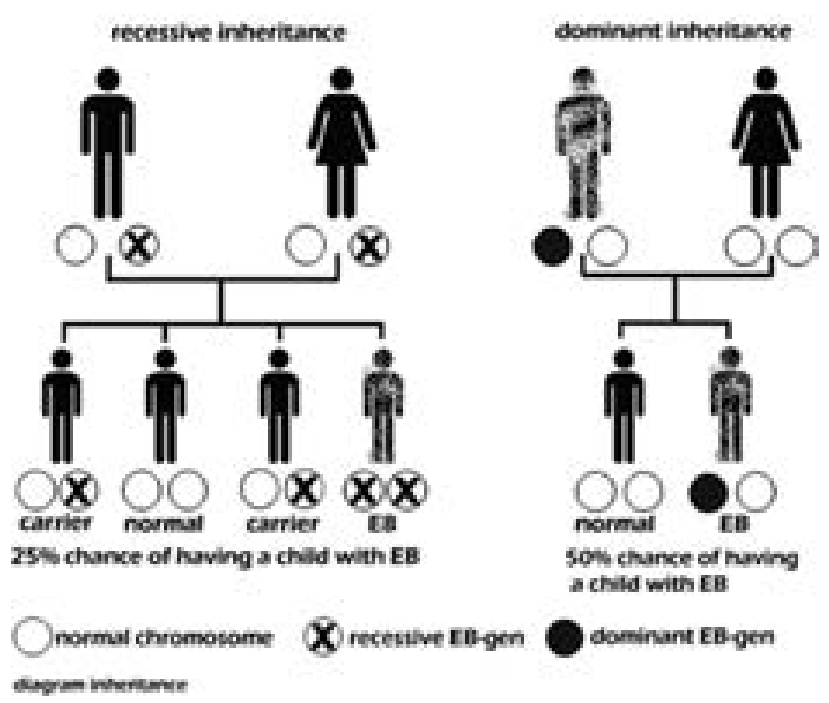

Gráfico 2. Herencia. 
vida y ocasionalmente están presentes al nacimiento, son inducidas por pequeños traumas y en los niños pequeños se ven principalmente en la espalda, manos y piernas. (3)

\section{Epidermolisis ampollar de la union (EAU)}

Se presenta con ampollas que se forman dentro de la lámina lúcida, por falla en los hemidesmosomas, Esta variedad puede afectar las mucosas oculares, cavidad bucal, vía urinaria, esófago y faringe, al igual que las uñas. En esta forma de $\mathrm{EB}$, existe una variedad potencialmente letal, llamada EB de la unión tipo Herlitz. (4)

\section{Epidermolisis ampollar distrófica (EAD)}

Presenta lesiones ampollares que se ubican entre la lámina densa y el estrato dérmico de la piel. Por tanto, la separación es subepidérmica, bajo la membrana basal, por rotura de las fibras de anclaje. La EB distrófica recesiva es una de las presentaciones clínicas más severas, en la que se pueden observar cicatrices en la piel y mucosas, vesículas y cicatrices en el esófago, el que puede presentar estenosis secundaria. Las ampollas generalizadas en la piel y mucosas pueden provocar retracción de la piel palmar de las manos y pies (7) Este fenómeno llamado pseudosindactilia, es producido por vesículas y úlceras cruentas a repetición en manos y pies, las que al cicatrizar dejan lesiones fibrosas que posteriormente se retraen y traccionan las zonas de los pliegues de los dedos, pudiendo incluso llegar a la reabsorción del hueso.

Sindrome de Kindler (SK), considerado hace poco como el cuarto tipo de EA (6) caracterizado por la formación de ampollas en distintos niveles, fotosensibilidad y poiquilodermia.

Los estudios (Prof. John McGrath) que se están llevando a cabo se basan en que la EB está causada por defectos en una o más de las proteínas que componen la piel. Estas proteínas están defectuosas porque los genes que las codifican tienen errores en el código.

Existen por tanto 3 tipos principales de EB, y 10 genes que codifican las proteínas de la piel:

\begin{tabular}{|c|c|c|c|}
\hline TIPOS DE EA & Numero de Subtipos & Herencia de subtipos & Genes afectados \\
\hline EAS & Aprox 12 subtipos & Dominante o recesiva & Queratina 5,14, Plectina \\
\hline EAU & Aprox 6 subtipos & recesiva & Colageno XVII, Integrina, Laminina \\
\hline EAD & Aprox 13 subtipos & Dominante o recesiva & Colágeno VII \\
\hline
\end{tabular}

Existe también una forma adquirida de EA que se presenta en la cuarta o quinta década de la vida y se debe a la producción de autoanticuerpos IgG contra el colágeno VII (6).

A su vez, estos tipos, según el gen alterado y en consecuencia la proteína que esté alterada o deficitaria tendrán distintas formas de presentación, severidad, extensión o compromiso extracutáneo dando lugar a los diferentes subtipos, mas de 33 desde los mas leves hasta los mas severos que dificultan la deambulación. Se ha establecido una nueva clasificación (3-8) dependiendo del tipo genético. 


\section{Pronóstico}

La EA presenta una gran variabilidad en su severidad. Los pacientes con las formas más leves pueden tener períodos de discapacidad temporal, pero pueden llevar vidas normales. Las formas más severas de EB pueden ser devastadoras física y emocionalmente, con la consecuencia de que el paciente esté totalmente inhabilitado y con discapacidad permanente.

\section{Características clínicas}

\section{Cutáneas}

Ampollas - erosiones - cambios de pigmentación - alopecía cicatrizal - ausencia o distrofia de uñas - piel de aspecto transparente y brillante pseudosindactilia - áreas de tejido de granulación en la zona perioral, cambios de pigmentación.

\section{Extracutáneas}

Estenosis a nivel del esófago y la laringe, anemia, retardo del crecimiento e injurias a nivel de las mucosas orales, conjuntivales y cornéales y mayor riesgo de carcinoma espino celular (CEC).

Las vesículas y ulceraciones se pueden infectar evolucionando ocasionalmente a celulitis o septicemia. Cicatrices extensas, algunas con fenómenos de retracción.

A nivel del esófago se observan mayoritariamente en la variedad de Epidermólisis ampollar distrófica recesiva EADR, en forma de estenosis, las cuales pueden llegar a imposibilitar el paso de los alimentos.

\section{Anemia}

Es común observar anemia crónica severa multifactorial en pacientes con la variedad EAU-H y EADR-HS. Se presume que sería multifactorial debido a una ingesta inadecuada, mala absorción secundaria, desnutrición crónica y pérdida crónica de hierro. Esta pérdida de hierro estaría dada por el sangrado crónico de erosiones y ulceraciones y a un estado inflamatorio crónico similar a la anemiadescrita en las enfermedades crónicas. (9)

\section{Complicaciones cardiológicas: Cardiomiopatía}

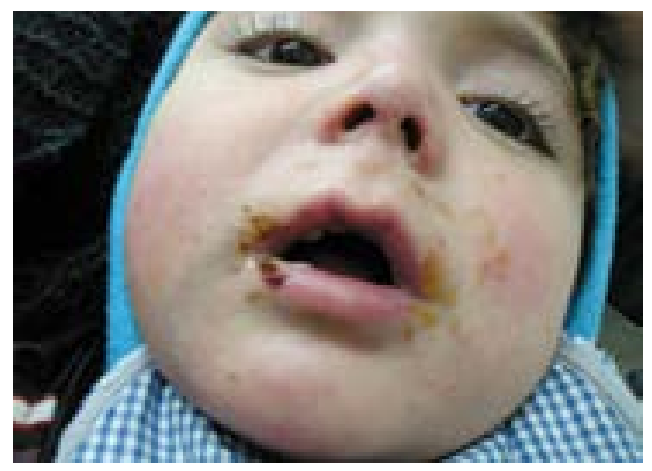

Figura 1. Lesiones cutáneas.

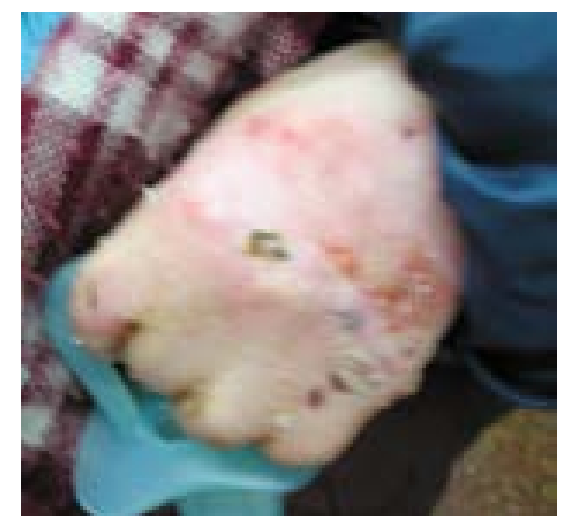

Figura 2.

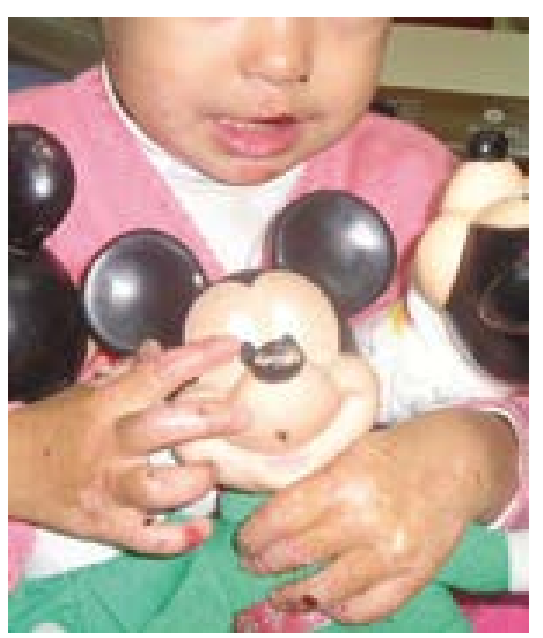

Figura 3. Manos. 


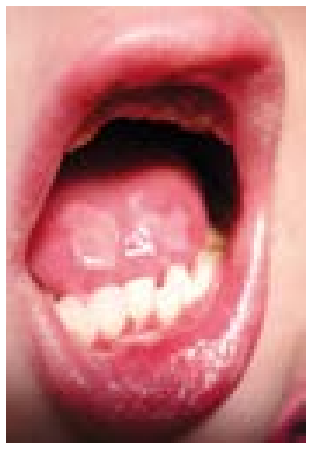

Figura 5. Ampollas en la lengua.

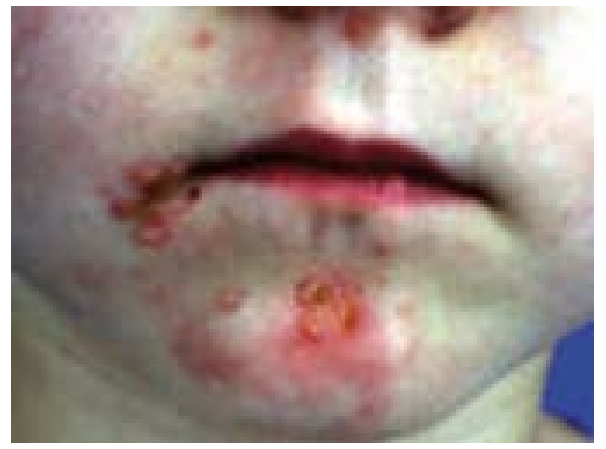

Figura 6.

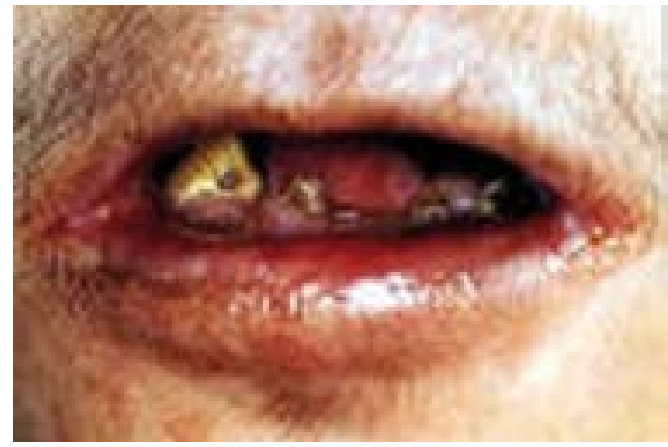

Figura 7. Anquilosis.

\section{Manifestaciones bucales (10 -12)}

- Ampollas intraorales.

- Microstomía.

- Anquiloglosia.

- Tendencia a transformación maligna de las lesiones.

\section{Tratamiento General}

El cuidado de un paciente con E.B. requiere, además de los cuidados dermatológicos, de un equipo multidisciplinario conformado por neonatólogos, pediatras, gastroenterólogos, odontólogos, terapistas ocupacionales, kinesiólogos, nutricionistas, traumatólogos, cirujanos plásticos, endoscopistas, Hematólogos, odontólogos y psicólogos (11).

Diariamente debe realizarse lo siguiente:

- Higienizar las heridas.

- Drenar las ampollas.

- Vendar en forma adecuada (protección).

- Prevenir infecciones.

- Promover una buena nutrición e hidratación.

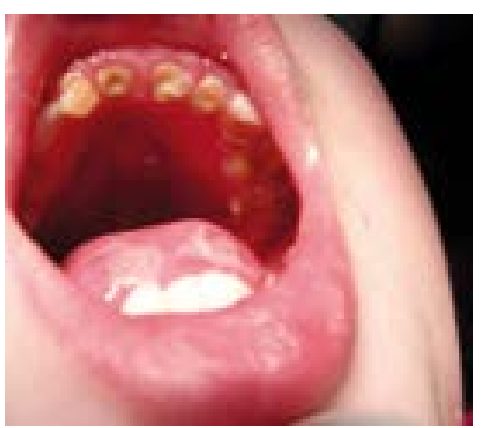

Figura 8. Caries.

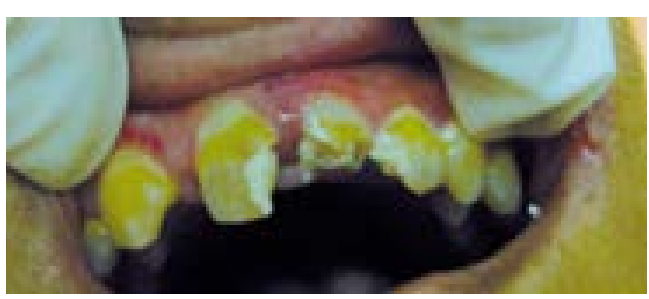

Figura 9. Hipoplasias caries.

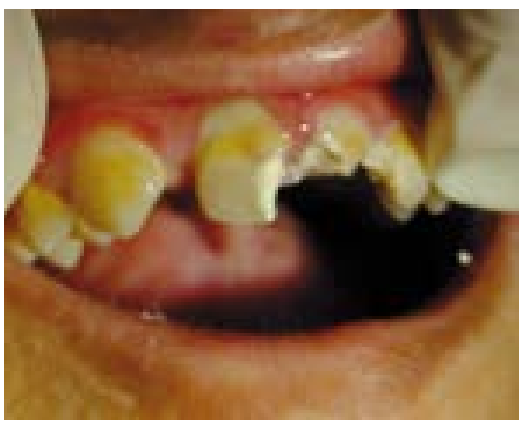

Figura 10. 


\section{Enfoque para la atención odontológica}

\section{Protocolo de atención odontológica}

- Paciente de alto riesgo médico. Coordinación con el equipo de salud a fin de evaluar procedimientos odontológicos y conducta a seguir de acuerdo al estado general. Derivación temprana para atención odontológica preventiva.

- Manejo apropiado de la conducta del niño, motivación para facilitar la situación odontológica (13).

- Procedimientos que eviten aparición de ampollas (Minimizar daños mediante lubricación) Envaselinar los labios y por lo general también se recomienda envaselinar el instrumental de examen. Antes de terminar la atención dental es importante revisar si se formaron ampollas, si existiesen se deben punzar con aguja estéril.

- Las prácticas que implican extracciones y tratamiento periodontal se realizan con control de Hematología.

- Necesidad prioritaria de controlar la infección bucal.

- Tratamiento dental con alto contenido Preventivo por Riesgo cariogénico aumentado aplicar flúor tópico en forma de barniz o gel. Es por eso que el control periódico, cada 3 a 6 meses.

- Control mecánico de biofilm: adaptación de cepillos dentales.

- Control químico de biofilm - Indicación de clorhexidine 0,12 a $1 \%$ y pasta remineralizante con Recaldent. Indicación de Fluor N-buches sin alcohol).
- Asesoramiento higiénico-dietético.

- Priorizar la Atención ambulatoria que incluya todas las especialidades odontológicas (14-16-17).

Es necesaria la capacitación del odontopediatra interactuando con el resto del equipo de salud, siguiendo el lineamento marcado por guías internacionales de manejo dental de pacientes con EA. (15)

\section{Situación clínica}

Paciente femenina, 11 años. Diagnóstico: Epidermólisis Ampollar distrófica recesiva.

Rehabilitación integral que requiere prótesis en atención ambulatoria, dedicando múltiples sesiones de motivación y realizando el tratamiento con extrema delicadeza.

Requirió supervisión hematológica por anemia crónica en las sesiones de extracciones dentarias.

Examen clínico de cavidad bucal:

- Presencia de ampollas en carrillos, piso de boca, lengua y rebordes alveolares.

- Disminución de apertura bucal.

- Anquiloglosia.

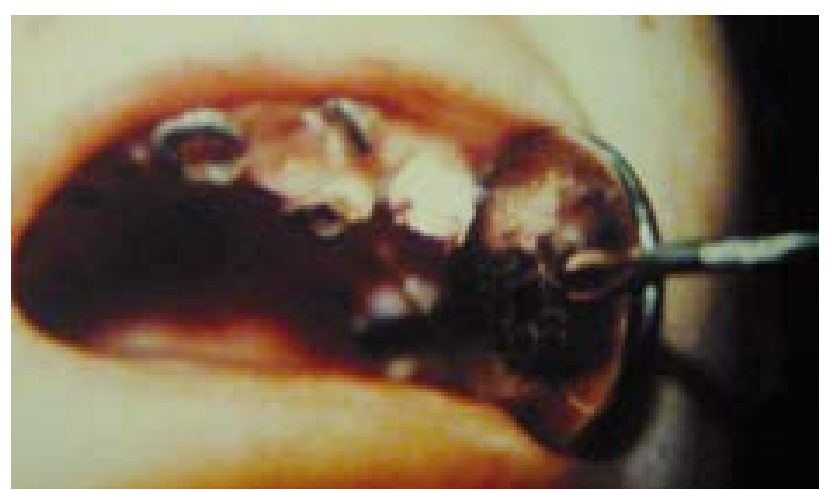

Figura 11. Policaries. 


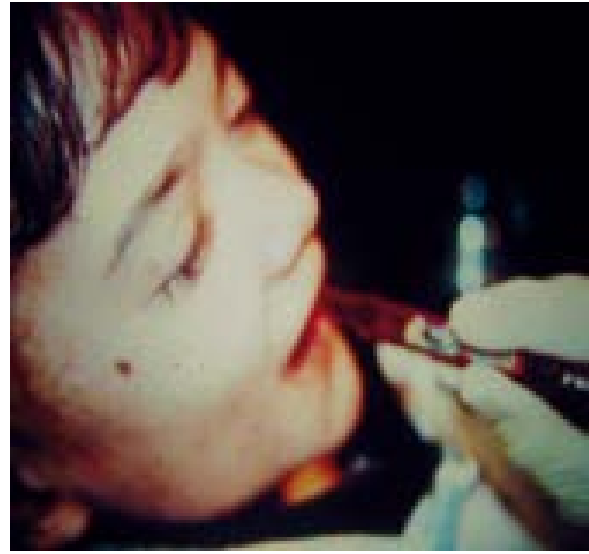

Figura 12. Cepillado.

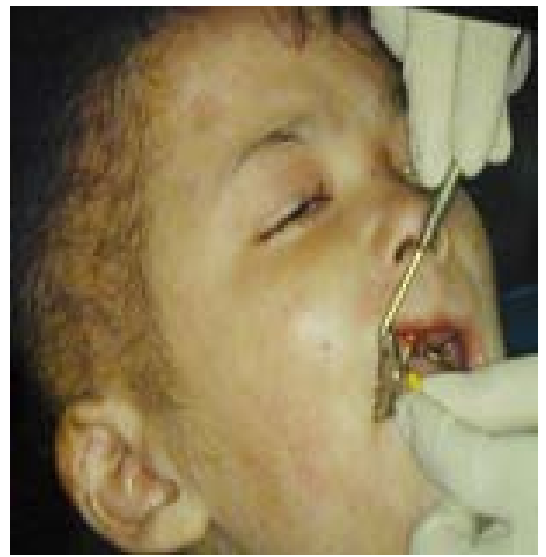

Figura 13. Endodoncia.

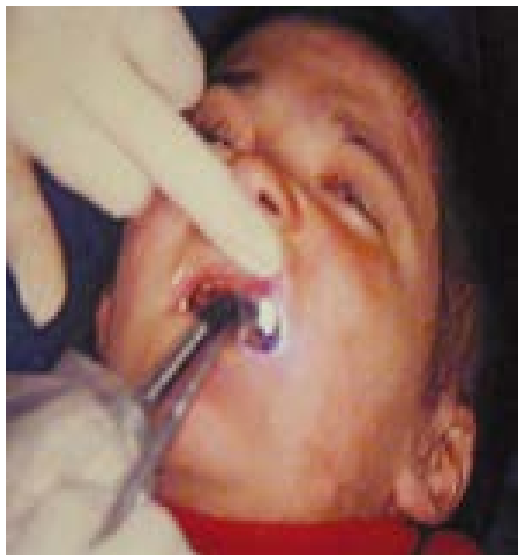

Figura 14. Extracciones.

- Presencia de abundante placa bacteriana.

- Caries penetrantes 13, 12, 11, 21, 22, 23, 33, 32, 31, 41, 42, 43, 15, 14, 24, 25.

- Caries NP 16, 27, 36, 35, 34, 44, 45, 46.

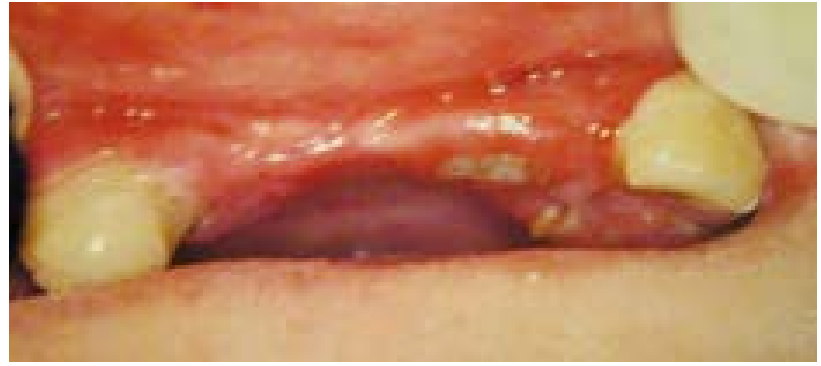

Figura 15. Reconstrucciones dentarias.

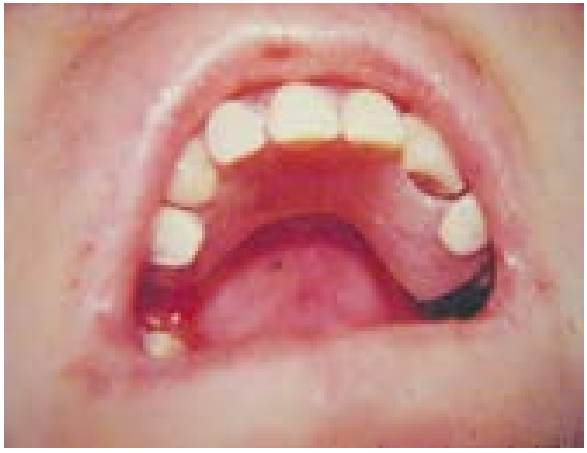

Figura 16. Prótesis bordes romos.

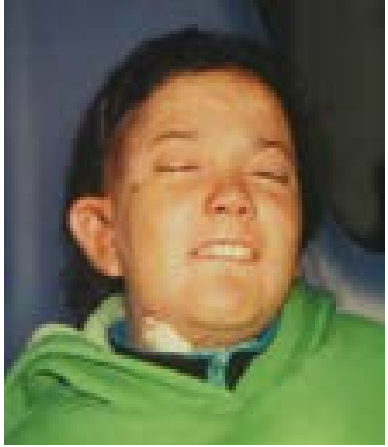

Figura 17. Rehabilitación integral.

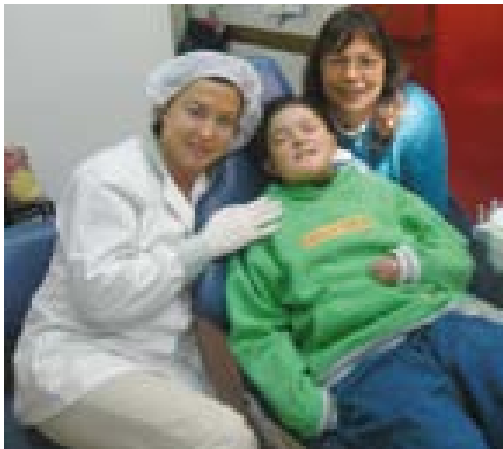

Figura 18. Vinculo odontopediatra, niña y familia.

\section{Conclusión}

Esta población de niños padece de dolor crónico debido a las manifestaciones propias de su enfermedad. Es muy difícili lograr una aceptable calidad de vida El concepto de prevención adquiere real importancia en la atención odontopediátrica de pacientes con EA, la que debe estar a cargo no sólo del odontólogo, si no de todo el equipo interdisciplinario de salud. La salud es un derecho y estos niños merecen la major calidad de odontología que el odontopediatra debe brindarle. 


\section{Referencias}

1.- Javier F. Feijoo, Juan Bugallo, Jacobo Limeres, David Peñarrocha, Miguel Peñarrocha, Pedro Diz.: Epidermólisis bullosa hereditaria. Actualización y sugerencias para el tratamiento dental. JADA Vol.6 nº6-2011.

2.- DEBRA International: disponible en URL http://www.debra-international.org/epidermolysis-bullosa/causes-andsubtypes.htm

3.- Fine JD, Eady RA Bauer EA Bauer JW Bruckner-Tuderman 4 Heagerty A Hintner H, Hovnanian A Report of the Third International Consensus Meeting on Diagnosis and Classification of EB . J Am Acad Dermatol. 2008 Jun;58(6):931-50. doi: 10.1016/j.jaad.2008.02.004. Epub 2008 Apr 18

4.- Momeni, A. \& Pieper, K. Junctional epidermolysis bullosa: a case report. Int.J.Paediatr.Dent. 15, 146-150 (2005).

5.-.Schumann H. Epidermolysis bullosa. An update. Hautarzt. 2009 Aug; 60(8):614-21.

6.- Chaudhari P, Marinkovich MP. What's new in blistering disorders? Curr Allergy Asthma Rep. 2007;7:255-63.

7.- Pye RJ: Bullous Eruptions. En Arthur Rook, D. S. Wilkinson. Textbook of Dermatology. Blackwell Scientific Publications 1986; 2; 1625-8.

8.- Fine JD. Inherited epidermolysis bullosa. Orphanet J Rare Dis. 2010 May 28;5:12.

9.- Horn HM, Tidman MJ. The clinical spectrum of dystrophic epidermolysis bullosa. Br J Dermatol. 2002 Feb;146(2):26774.

10.- Pekiner FN, Yücelten D, Ozbayrak S, Sezen EC. Oral-clinical findings and management of epidermolysis bullosa. J Clin Pediatr Dent. 2005 Fall;30(1):59-65. Review.

11.- Pope E, Lara-Corrales I, Mellerio J, Martinez A, Schultz G, Burrell R, Goodman L, Coutts P, Wagner J, Allen U, Sibbald G. A consensus approach to wound care in epidermolysis bullosa. J Am Acad Dermatol. 2012 Nov;67(5):904-17

12.- Kramer, S. M. Oral care and dental management for patients with epidermolysis bullosa. Dermatol.Clin. 28, 303-9, $x(2010)$.

13.- Scagnet G, Cap.25 Odontopediatría en niños con discapacidad. Odontopediatría-Fundamentos y prácticas para la atención personalizada - Aut:.Biondi AM,Cortese S, 437-453, Alfaomega Ed., 2010.

14.-Scagnet G, Cap 18 Enfermedades Raras en Odontología en Pacientes Especiales Aut.:Morales Ch.M. 165-186. Colson,CA Ed. 2012

15.- Krämer SM, Serrano MC, Zillmann G, Gálvez P, Araya I, Yanine N, Debra International et al.: Oral health care for patients with epidermolysis bullosa--best clinical practice guidelines. Int J Paediatr Dent. 2012 Sep;22 Suppl 1:1-35.

16.- Lindemeyer R, Wadenya R, Maxwell L.: Dental and anaesthetic management of children with dystrophic epidermolysis bullosa. Int J Paediatr Dent. 2009 Mar; 19(2):127-34.

17.- Serrano Martínez C, Silvestre Donat FJ, Bagán Sebastián JV, Peñarrocha Diago M, Alió Sanz JJ. Hereditary epidermolysis bullosa. Dental management of three cases. Med Oral. 2001 Jan-Feb;6(1):48-56. English, Spanish

Revisión y traducción de portugués: Fabián Calixto Fraiz

Recibido 29-06-2013

Aceptado: 12-07-13

Correspondencia gabrielascagnet@hotmail.com 